\title{
Improving the writing of research papers: IMRAD and beyond
}

\author{
Jianguo Wu
}

Published online: 5 November 2011

(C) Springer Science+Business Media B.V. 2011

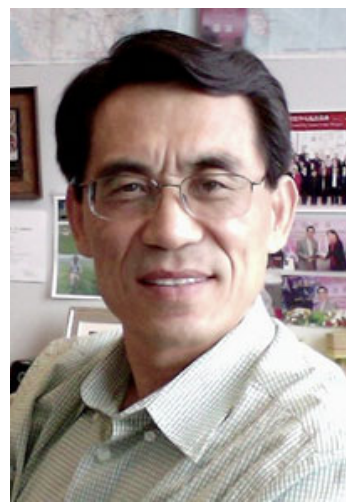

Publishing in peer-reviewed journals is essential to scientific research. "A scientific experiment, no matter how spectacular the results, is not completed until the results are published" (Day and Gastel 2006). Advances in science depend on the rigorous process of scientific publishing. Justified or not, journal impact factors and article citations have become the buzzwords in today's academic world, and have been used increasingly as metrics to evaluate the performance of research projects, journals, scientists, and institutions.

J. Wu ( $₫)$

School of Life Sciences and Global Institute of Sustainability, Arizona State University, Tempe, AZ 85287, USA

e-mail: Jingle.Wu@asu.edu
As scientific journals and published articles continue to proliferate, we as editors, reviewers, and scientists all are faced with increasing challenges to communicate science more effectively and efficiently.

In this series of editorials, we focus on the question: How can we improve our writing of research papers for Landscape Ecology and other professional journals to increase their readability and facilitate the process of their evaluation? Obviously, this is not a new question; nor do we promise to have revolutionary answers. Experts have written numerous books and journal articles addressing this very topic. The main goal here is to discuss several key issues on the organization of research papers-particularly on the structure of IMRAD (introduction-methods-resultsand-discussion) - the predominant format of scientific writing. I hope that our editors, reviewers, and authors will benefit from this discussion.

\section{IMRAD as an outcome of the evolution of scientific publishing}

Everyone in science may know something about IMRAD — the introduction-methods-results-anddiscussion structure (Fig. 1). But its history is rather brief when compared to that of scientific writing as a whole. The first scientific journals appeared in the 17th century, when articles were published mainly in the form of descriptive letters and narratives structured chronologically (Meadows 1985; Day 1989). For more 


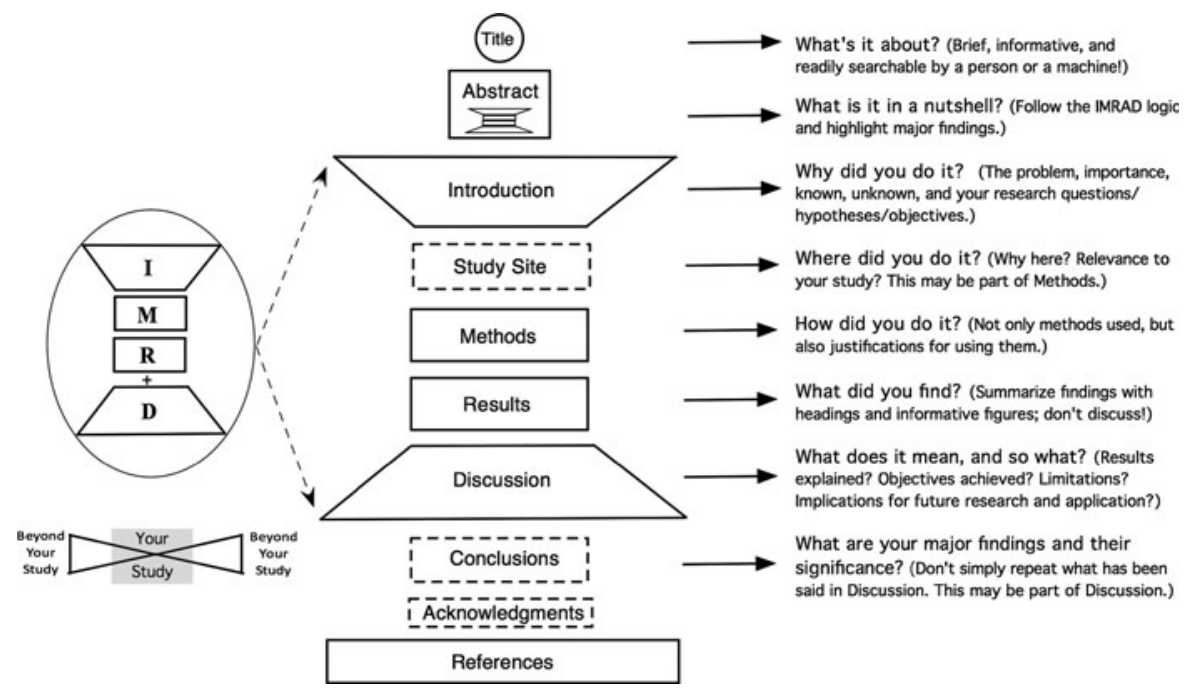

Fig. 1 Diagrammatic representation of the IMRAD structure of research papers (modified from a diagram at http://www.services. unimelb.edu.au/asu/writing/). The basic structure of IMRAD has only four sections: introduction (I), methods (M), results (R), and discussion (D). Most original research papers today have 6-10 sections, with those in dotted-lined boxes being optional. The

than two centuries, scientific papers were published without a generally accepted format. During this period of time, however, the idiosyncrasy in scientific publishing gradually withered as both the journals and the papers in them became increasingly formalized by developing some form of organization in structure (Meadows 1985). Day (1989) argued that it was Louis Pasteur who invented the first IMRAD-like writing structure in his classic book, Etudes sur la Biere (studies on fermentation), originally published in 1876. Pasteur's book had identifiable sections of "introduction", "methods", and "discussion"-although such headings were not explicitly used (Day 1989). However, IMRAD did not become the "standard" until the 1970s, when the American national standard for the preparation of scientific papers for written or oral presentation (ANSI Z39.16-1972) was published in 1972 and again 1979 (Day 1989; Day and Gastel 2006).

IMRAD began to be adopted by scientific journals around the 1940s, and quickly became the dominant format for research papers in a majority of leading scientific journals by the late 1970s. For example, for leading journals in medical research IMRAD was adopted in the 1950s, became predominant in the 1960s, and has been the standard since the 1980s shape of each section is meaningful as it suggests how that section should proceed in terms of specificity (focusing on your study) and generality (relating to studies by others). The size of each box is roughly proportional to the relative length of each section. The text with arrows indicates what main questions each section should address

(Sollaci and Pereira 2004). In physics, IMRAD was already employed extensively in the 1950s (Bazerman 1984). Research papers in two of the most prominent ecological journals, Journal of Ecology (published by British Ecological Society since 1913) and Ecology (published by Ecological Society of America since 1920), began to adopt IMRAD in the 1950s. For instance, Lindeman's (1942) seminal article on trophic dynamics in Ecology was organized by topics, but the classic paper on vegetation continuum by Curtis and McIntosh (1951) in the same journal clearly was IMRAD-structured. In Journal of Ecology, Watt's (1947) masterpiece on pattern and process in plant communities was also organized with topical headings, but Pielou's (1957) paper-one of the earliest about scale effects on characterizing spatial patternshad the appearance of IMRAD. Today, IMRAD is the standard for all major journals in ecology, including this one-Landscape Ecology.

Why has IMRAD been adopted by almost all research journals so widely and quickly, with no sign of being abandoned anytime soon? According to Meadows $(1985,1998)$, changing the internal organization of research papers is one way for the scientific community to respond to the exponential growth of 
scientific information, and thus IMRAD is a result of that evolutionary process. Most, if not all, editors and scientists agree that IMRAD provides a consistent framework that guides the author to address several questions essential to understanding a scientific study (Fig. 1): Introduction-Why did you do it in the first place? Methods-How did you do it exactly? Results-What did you find? Discussion-What does it mean after all and so what? According to experts who specialize in the history and practice of scientific writing, IMRAD offers several benefits (Meadows 1998; Sollaci and Pereira 2004; Day and Gastel 2006). The modular structure of IMRAD helps the author to organize ideas and remember critical elements; it makes easier for the editor and the reviewer to evaluate manuscripts; and it improves the efficiency of the scientist to locate specific information without going through the entire paper.

\section{IMRAD as an adaptable structure for research papers}

IMRAD is primarily for original research articles, and has little relevance to other types of papers commonly seen in scientific journals, such as reviews, perspectives, and editorials. Even for research papers, IMRAD is silent about several other components of a modern research paper: title, abstract, acknowledgments, and references. It does not even say anything about how the sections of I, M, R, and D should each be constructed. So, IMRAD is not really a straightjacket. It has plenty of room for creativity and innovation.

Dozens of books and hundreds of articles have been published on scientific writing, and most if not all of them offer advice on what each element of IMRAD ought to include. One problem to new writers, however, is that these different guides seem to differ in the details. After handling hundreds of manuscripts for Landscape Ecology, I observed that a considerable portion of them had various structural problems. Two of them are major. One is the lack of clearly identified research problems and questions in the introduction (or elsewhere). The other is the lack of organization within each section (particularly results and discussion) - the reader needs to see a building, not a pile of bricks! I have seen manuscripts with an introduction section running several pages long without mentioning the research question of the study, and a discussion section of more than 3 pages without any headings.

How should one resolve the above-mentioned problems? There is no panacea, but I have two suggestions for improvements. First, I find the diagrammatic representation of IMRAD (Fig. 1) quite useful because it captures the essence of the structure. The shape and the size of each section are heuristic and easy to remember. My second suggestion is to consult a good writing guide for specifics of each section, from the title to the references. Every experienced author may have a favorite, and mine is Day and Gastel (2006). Another excellent guide is Gustavii (2008), which is a comprehensive yet succinct account of the essentials of scientific writing (particularly helpful to authors whose native language is not English). Also, for those who prefer more detailed instructions about key elements within each section, Hartley's (1999) "modest proposal"-IMRAD nested with topical headings/subheading in each section-should be helpful. In addition, being precise and concise in language is quintessential in scientific writing. This is a tall order. To get help, a must-have reference is the timeless "little book"-The Elements of Style (Strunk and White 2000).

Don't try to read every guide that you can find. Don't read it and rest it. Keep it handy, and consult it frequently while writing.

\section{IMRAD as an evolutionary process}

As discussed above, the format of scientific papers has evolved during the past several centuries, and will continue to evolve. The evolution of the article format is more than just a way of coping with the everincreasing kinds and amount of information. As Meadows (1985) stated:

"The construction of an acceptable research paper reflects the agreed view of the scientific community on what constitutes science. A study of the way papers are constructed at any point in time therefore tells us something about the scientific community at that time."

As science and information technology continue to advance, IMRAD will undoubtedly evolve as well. In fact, changes have already taken place. For example, 
abstract, keywords, acknowledgments, and references have become common parts of the IMRAD structure. Even the sequential order of the sections is altered in some journals (e.g., Nature places the methods section, in smaller font size, at the end of a research paper).

Since the early 1990s, structured abstracts—which are organized into several sections with headings or sequential numbers-have become increasingly common in scientific journals. A common format of structured abstracts is: Abstract [background, aims (or objectives), methods, results, conclusions (or synthesis)]. Many leading journals in medical and physical sciences now have them. Some ecology journals have also jumped on this bandwagon, such as those of British Ecological Society. Studies have shown that structured abstracts have several advantages for both authors and readers. For example, Hartley (2003) found that structured abstracts tend to be significantly more informative, more readable, and clearer than unstructured, traditional abstracts. Hartley and Betts (2007) concluded that “... spatial organization, together with the greater amount of information normally provided in structured abstracts, explains why structured abstracts are generally judged to be superior to traditional ones." This should make immediate sense to landscape ecologists—isn't this another example of pattern affecting process?

A good abstract should be complete, concise, and clear. That is, an abstract should have all the components necessary for a short but complete story. A condensed version of IMRAD, with greater emphasis on results and discussion, is commonly assumed in an abstract. While being complete, an abstract must also be succinct because most journals require that it be no longer than 250-300 words. In addition, a good abstract must have a clear message — what's the story and so what? Assuming it is a solid study, the abstract should not be difficult to write after all sections of the paper are completed. In reality, however, it is too easy to find abstracts that are either empty in contents or devoid of any recognizable organization. I think that structured abstracts can help improve upon these problems. The structured format guides the author to tell a complete story in a nutshell, and facilitates a faster search for relevant information by either a human reader or a computerized search engine. A useful message for authors is this: always write your abstract following the logical order of structured abstracts even if your target journal does not require a structured abstract.

There are certainly other ways to improve the adaptive application of IMRAD. A number of experts in linguistics and scientific writing have done a great deal of research on this subject. For example, Hartley (1999) proposed to go "from structured abstracts to structured articles" with a more elaborated IMRAD organization. Sharp (2002) advised the application of the six W's (what, why, when, how, where, and who) in each section of IMRAD as a way of providing more structuring.

More relevant to the readers of this journal, Gustafson (2011) made several thought-provoking suggestions for improving scientific writing in landscape ecology. The 7-section structure that he proposed may be considered a modification to the traditional IMRAD. The headings and subheadings in the 7 sections can fit into the IMRAD structure and provide more organization in a way similar to Hartley (1999). As discussed earlier, structuring scientific writing helps avoid missing important elements and facilitates fast retrieval of information. As Riitters (2011) warned, however, too much structuring may hinder the creative process of writing. In addition, because spatiotemporal patterns are central to most landscape ecological studies, graphical communication and metadata documentation are critically important to scientific publishing in our field. Henebry (2011) provided a brief but resourceful guide to improving the quality of graphs (particularly maps) and ensuring valuable metadata to persist. I highly recommend writers to bear his advice in mind: "Structure your story around the graphs and enable the captions to capture the key points of your paper."

\section{Concluding remarks}

Peter Medawar, the British biologist and a Nobel Laureate in Physiology/Medicine, famously said that the scientific paper is a fraud "because it misrepresents the processes of thought that accompanied or gave rise to the work that is described in the paper" (Medawar 1964). He argued that discussion in an IMRADstructured paper should be placed at the beginning, which then is followed by results and methods. Meadows (1985) disagreed, and argued that the scientific paper is an archaeological artifact indicative 
of how scientists generally view their science at a particular time.

It is true that IMRAD does not always represent the order of actual research activities, but that alone does not make the scientific paper fraudulent. While IMRAD seems reflective of the currently dominant view of what is scientific, the format of the scientific paper may be influenced increasingly by technological advances in information processing and publishing as well as the pace of knowledge production. For now, IMRAD still rules, and modifications will continue.

Riitters (2011) had a great line: "creativity abhors prescription and well-documented junk is still junk." While this statement is fundamentally correct, I believe that scientific writing should be disciplined and structured for all the reasons that I have discussed earlier. I also believe that it has been, and will continue to be, true that "the best papers combine the science ..... with the art of writing" (Southgate 1995). Properly using IMRAD improves the art of writing as well as the communication of the science. No, "Good prose cannot correct bad work" (Sharp 2002), but good prose can make good work better-sometimes, so dramatically better!

\section{References}

Bazerman C (1984) Modern evolution of the experimental report in physics: spectroscopic articles in physical review, 1893-1980. Soc Stud Sci 14:163-196

Curtis JT, McIntosh RP (1951) An upland forest continuum in the prairie-forest border region of Wisconsin. Ecology 32:476-496

Day RA (1989) The origins of the scientific paper: the IMRAD format. AMWA Journal 4:16-18
Day RA, Gastel B (2006) How to write and publish a scientific paper (6th ed). Greenwood Press, Westport. (Also, Day RA (1998) How to write and publish a scientific paper, 5th ed. Oryx Press, Phoenix)

Gustafson EJ (2011) Publishing landscape ecology research in the 21 st century. Landscape Ecol. doi:10.1007/s10980011-9638-7

Gustavii B (2008) How to write and illustrate a scientific paper, 2nd edn. Cambridge University Press, Cambridge

Hartley J (1999) From structured abstracts to structured articles: a modest proposal. J Tech Writ Commun 29:255-270

Hartley D (2003) Improving the clarity of journal abstracts in psychology. Sci Commun 24:366-379

Hartley J, Betts L (2007) The effects of spacing and titles on judgments of the effectiveness of structured abstracts. J Am Soc Inf Sci Technol 58:2335-2340

Henebry GM (2011) Beyond words: effective graphics and metadata are keys to concise scientific communication. Landscape Ecol. doi:10.1007/s10980-011-9672-5

Lindeman RL (1942) The trophic-dynamic aspect of ecology. Ecology 23:399-418

Meadows AJ (1985) The scientific paper as an archaeological artifact. J Inf Sci 11:27-30

Meadows AJ (1998) Communicating research. Academic Press, San Diego

Medawar PB (1964) "Is the scientific paper fraudulent?" Saturday Review, 1 August 1964, 42-43

Pielou EC (1957) The effect of quadrat size on the estimation of the parameters of Neyman's and Thomas's distributions. J Ecol 45:31-47

Riitters K (2011) Creativity abhors prescription. Landscape Ecol. doi:10.1007/s10980-011-9673-4

Sharp D (2002) Kipling's guide to writing a scientific paper. Croatian Med J 43:262-267

Sollaci LB, Pereira MG (2004) The introduction, methods, results, and discussion (IMRAD) structure: a fifty-year survey. J Med Libr Assoc 92:364-367

Southgate DAT (1995) The structure of scientific papers. Br J Nutr 74:605-606

Strunk W Jr, White EB (2000) The Elements of style, 4th edn. Allyn \& Bacon, Boston

Watt AS (1947) Pattern and process in the plant community. J Ecol 35:1-22 